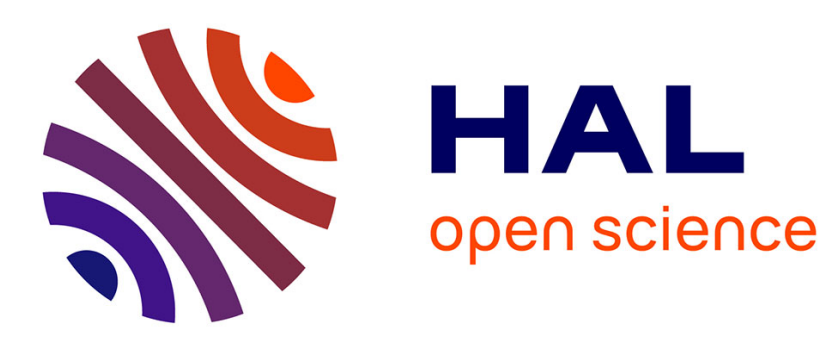

\title{
Excitation mechanisms and localization sites of erbium-doped porous silicon
}

Adel Najar, Habib Elhouichet, Nathalie Lorrain, Mehrezi Oueslati

\section{To cite this version:}

Adel Najar, Habib Elhouichet, Nathalie Lorrain, Mehrezi Oueslati. Excitation mechanisms and localization sites of erbium-doped porous silicon. Applied Surface Science, 2006, 252 (16), pp.5808-5813. 10.1016/j.apsusc.2005.07.071 . hal-00145924

\section{HAL Id: hal-00145924 https://hal.science/hal-00145924}

Submitted on 9 Nov 2021

HAL is a multi-disciplinary open access archive for the deposit and dissemination of scientific research documents, whether they are published or not. The documents may come from teaching and research institutions in France or abroad, or from public or private research centers.
L'archive ouverte pluridisciplinaire HAL, est destinée au dépôt et à la diffusion de documents scientifiques de niveau recherche, publiés ou non, émanant des établissements d'enseignement et de recherche français ou étrangers, des laboratoires publics ou privés.

\section{다)(1) $(5$}

Distributed under a Creative Commons Attribution - NonCommercial| 4.0 International 


\title{
Excitation mechanisms and localization sites of erbium-doped porous silicon
}

\author{
A. Najar ${ }^{\text {a }}$, H. Elhouichet ${ }^{\mathrm{a}, *}$, N. Lorrain ${ }^{\mathrm{b}}$, M. Oueslati ${ }^{\mathrm{a}}$ \\ ${ }^{a}$ Unité de recherche de Spectroscopie Raman, Département de Physique, Faculté des Sciences de Tunis, Elmanr 2092, Tunis, Tunisia \\ ${ }^{\mathrm{b}}$ Equipe "Matériaux poreux et dispositifs pour l'Optique guidée", Laboratoire d'Optronique, UMR 6082, 22300 Lannion, France
}

\begin{abstract}
Porous silicon (PS) is doped with erbium by electrochemical anodisation. The penetration of erbium into the PS layer is confirmed by Rutherford backscattering spectroscopy (RBS) and energy dispersive X-ray (EDX) measurements. Efficient green and infrared emissions were observed at room temperature. The investigations are focused on the evolutions versus temperature and pump intensity of the green photoluminescence (PL) corresponding to the ${ }^{4} \mathrm{~S}_{3 / 2} \rightarrow{ }^{4} \mathrm{I}_{15 / 2}$ transition. It was found that an erbium related level defect can be involved on the excitation and emission processes of erbium. Pump intensity dependent PL studies revealed that for the electrochemical incorporation, most of the $\mathrm{Er}^{3+}$ ions are localized inside the $\mathrm{Si}$ nanocrystallites and not in stoichiometric $\mathrm{SiO}_{2}$. The optical cross-section is close to that of erbium in Si nanocrystallites.
\end{abstract}

Keywords: Porous silicon; Erbium; Excitation mechanisms; Cross-section

\section{Introduction}

Erbium-doped silicon has been studied for over a decade for possible applications in optoelectronics and in telecommunication because erbium can emit photons at $1.54 \mu \mathrm{m}$ due to an intra 4f shell transition between the ${ }^{4} \mathrm{I}_{13 / 2}$ and the ${ }^{4} \mathrm{I}_{15 / 2}$ levels. This emission is particularly attractive since its wavelength falls inside a window of maximum transmission for silica optical fibers. The development of practical, silicon-based

\footnotetext{
* Corresponding author. Tel.: +216 71872600; fax: +216 885073
} E-mail address: habib.elhouichet@fst.rnu.tn (H. Elhouichet). light emitting devices, however, has been severely limited by a low erbium concentration and strong quenching of photoluminescence (PL) intensity. Several alternative ways are currently being pursued in order to deal with its inability to luminescence efficiently. Porous silicon (PS) is considerate an appropriate material for erbium doping because its visible PL is efficient and is compatible with standard silicon processes in making integrated optoelectronic devices [1]. It's very large surface area to volume ratio makes the PS matrix very accessible for erbium doping, as well as a host for large concentrations of oxygen necessary for erbium emission. Doping of PS 
with rare-earth (RE) ions has been achieved by ion implantation [2], diffusion [3], dip-coating [4] and electrochemical deposition $[5,6]$. Cathodic electrochemical deposition is preferred because it offers the advantages of deeper erbium penetration (10-20 $\mu \mathrm{m})$, lower cost, and simplicity of processing. The question here is where in PS are located $\mathrm{Er}^{3+}$ ions, when PS consists of various crystalline and amorphous phase, and how $\mathrm{Er}^{3+}$ ions are excited from the $\mathrm{c}-\mathrm{Si}$ nanocrystallites?

In this work, we have doped PS with erbium by electrochemical deposition. Erbium profile in the PS layer is studied from the Rutherford backscattering spectroscopy (RBS) and energy dispersive X-ray (EDX) measurements. The dependencies of PL intensity versus temperature and pump intensity are investigated. The processes of erbium excitation and de-excitation in porous silicon are discussed.

\section{Experimentation}

We used PS samples prepared by anodising a p-type $\left(\begin{array}{lll}1 & 0 & 0\end{array}\right)$ silicon substrate $(0.7-1.3 \Omega \mathrm{cm})$ in a mixture of $\mathrm{HF}(40 \%)$ and ethanol $\left(\mathrm{HF}: \mathrm{C}_{2} \mathrm{H}_{5} \mathrm{OH}=1: 1\right)$ with a current density of $12 \mathrm{~mA} / \mathrm{cm}^{2}$. The anodisation time is chosen to obtain a PS thickness less than $4 \mu \mathrm{m}$. Using the gravimetric method, the porosity of the PS layer is estimated to $65 \%$.

Erbium is introduced into the PS by electrochemical deposition from a saturated chloride solution of erbium $\left(\mathrm{ErCl}_{3}: \mathrm{C}_{3} \mathrm{H}_{5} \mathrm{OH}\right)$ for $30 \mathrm{~min}$ at a current density of $0.1 \mathrm{~mA} / \mathrm{cm}^{2}$. After erbium deposition, the sample is rinsed with ethanol in order to clean the surface, and then is subjected to two classic thermal annealing (CTA) at $300{ }^{\circ} \mathrm{C}$ for $30 \mathrm{~min}$ and at $1000{ }^{\circ} \mathrm{C}$ for $20 \mathrm{~min}$ to activate the erbium ions in the matrix.

In order to study the incorporation of erbium in the PS, the penetration was controlled by Rutherford backscattering spectroscopy (RBS) of ${ }^{4} \mathrm{He}^{+}$ions delivered by a $2 \mathrm{MeV}$ Van de Graf accelerator and energy dispersive X-ray (EDX) analysis.

Photoluminescence (PL) measurements are performed by using the $488 \mathrm{~nm} \mathrm{Ar}^{+}$line as excitation source, a triple monochromator for light analysis and a "GaAs" photomultiplier. For infra-red PL measurements, an InGaAs photodiode is used. The sample temperature was controlled from 20 to $300 \mathrm{~K}$ by a closed cycle He cryostat.

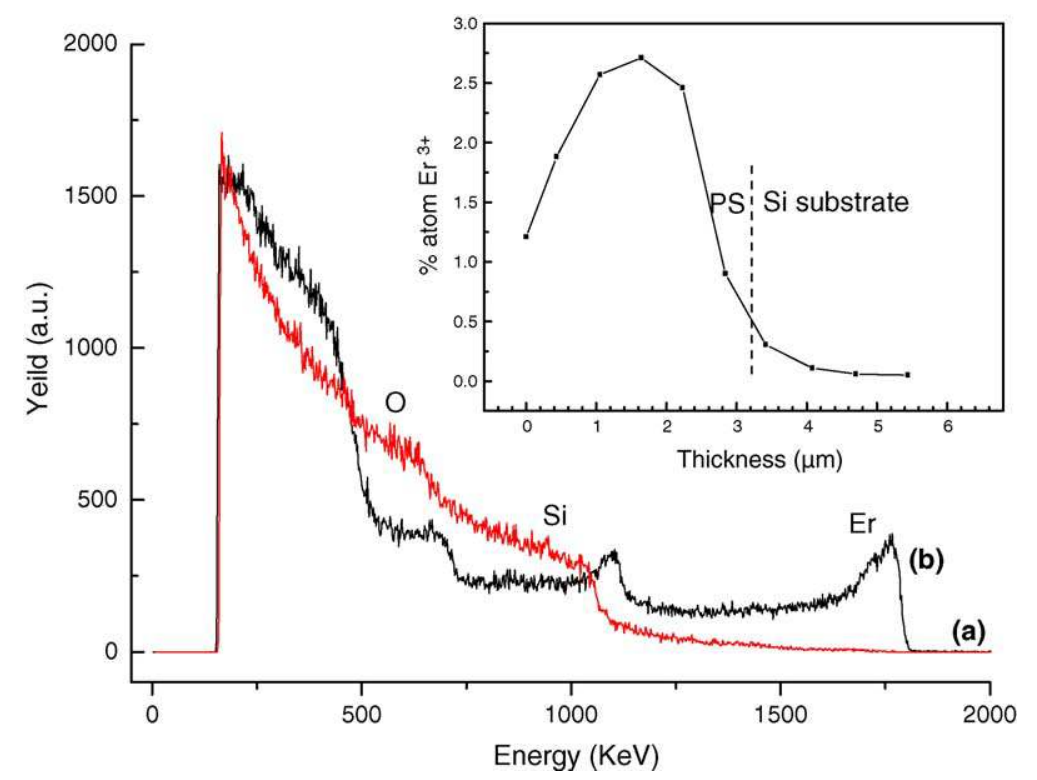

Fig. 1. RBS spectra of porous silicon (a) and erbium-doped porous silicon (b). Inset: concentration of erbium, deduced from EDX analyses, in different region of the PS layer. 


\section{Results and discussion}

Fig. 1 presents the RBS spectra of undoped PS layer and the same PS layer doped erbium after subsequent annealing. The energies corresponding to erbium, silicon, and oxygen located at the sample surface are indicated. The high energy position (1200$1780 \mathrm{keV}$ ) is related to erbium profile into the PS layer. It is clear from the figure that erbium concentration increases from the top surface of the PS layer and is quite constant in the middle part. Further informations on erbium incorporation on the host are given from EDX measurements performed on SEM cross-section of the PS layer (inset of Fig. 1). The results show that the atomic percentage of erbium increases from $1.4 \%$ at the top region of the layer to $2.7 \%$ at the middle part and then decreases to $0.2 \%$ at the interface PS/Si. These results are in agreement with the RBS measurements.

Fig. 2 shows the PL spectra, in the visible and IR regions of erbium-doped PS after annealing at $1000{ }^{\circ} \mathrm{C}$ in air. The relatively strong transitions at $18,500 \mathrm{~cm}^{-1}(0.540 \mu \mathrm{m})$ and $18,235 \mathrm{~cm}^{-1}(0.548$ $\mu \mathrm{m})$ correspond to the green emissions from the ${ }^{2} \mathrm{H}_{11 / 2}$ and ${ }^{4} S_{3 / 2}$ levels to ${ }^{4} \mathrm{I}_{15 / 2}$, respectively. The IR PL peaks localized at 0.98 and $1.53 \mu \mathrm{m}$ correspond to the ${ }^{4} \mathrm{I}_{11}$ / ${ }_{2} \rightarrow{ }^{4} \mathrm{I}_{15 / 2}$ and ${ }^{4} \mathrm{I}_{13 / 2} \rightarrow{ }^{4} \mathrm{I}_{15 / 2}$ transitions, respectively. The PL band at $1.14 \mu \mathrm{m}$ is relative to IR emission from bulk $\mathrm{Si}$. These results prove the existence of erbium into the PS layer. The PL peaks are not well resolved indicating that probably erbium activation in the host is not completely performed or the $\mathrm{Er}^{3+}$ ions occupy multi-sites in Si nanocrystallites and other part of the ions are dispersed in the $\mathrm{SiO}_{x}$ phase. Oxygen atoms may be effectively incorporated deep into the pores of porous silicon and $\mathrm{Er}-\mathrm{O}$ complexes may be formed [7].

Erbium ions can be located in c-Si nanacrystallites or in the untiring amorphous $\mathrm{SiO}_{x}$ phases. In both cases, energy transfer can occur to erbium ions. It is known that in ordered semiconductor, RE ions create trap level localized in the band gap. RE excitation is a result of the thermalisation of carriers localized at RE trap level [8]. For $\mathrm{Er}^{3+}$ in amorphous $\mathrm{SiO}_{x}$, excitation transfer occurs because the ions are located within a few nanometres of the c-Si nanocrystallites. The formed excitation inside the c-Si nanocrystallites can be subsequently transferred to the erbium ion.
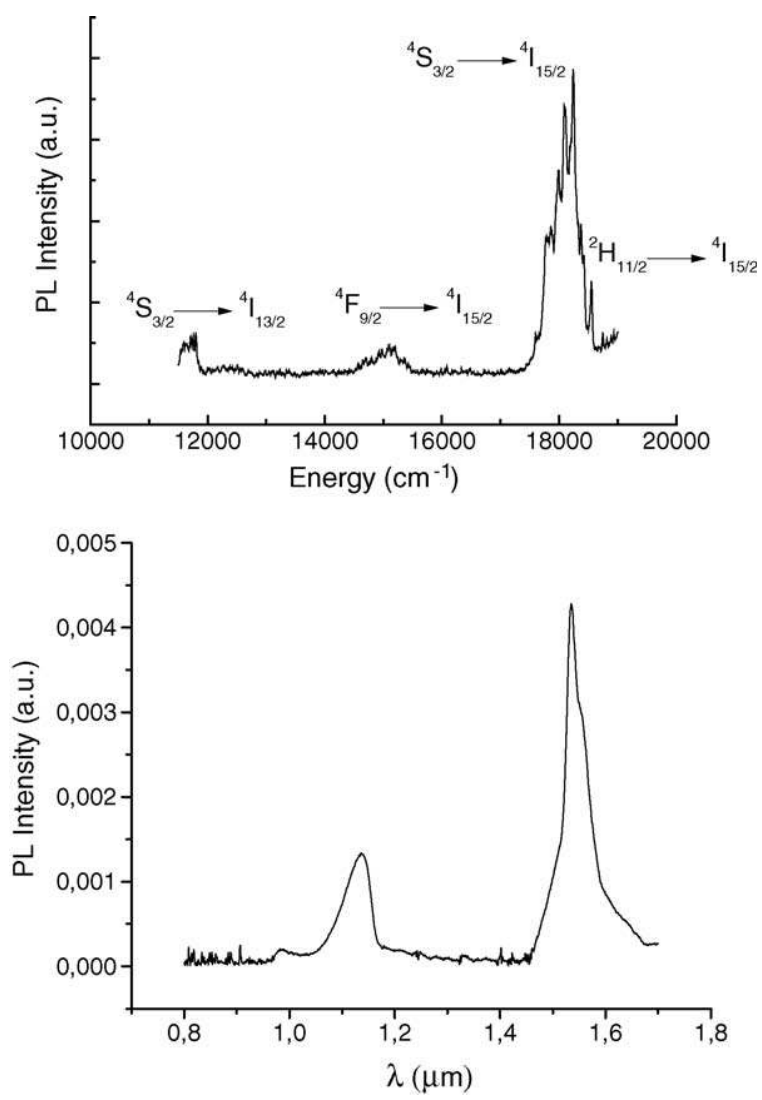

Fig. 2. PL spectra of erbium-doped PS, at room temperature after annealed at $1000{ }^{\circ} \mathrm{C}$, in the visible and IR ranges.

The evolution of the PL intensity relative to the ${ }^{4} \mathrm{~S}_{3 /}$ ${ }_{2} \rightarrow{ }^{4} \mathrm{I}_{15 / 2}$ transition is studied versus temperature. The PL intensity is kept practically constant at low temperature and quenches significantly with increasing temperature. Such temperature behaviour is a result of the thermalisation of carriers localized at erbium trap level [8,9] indicating a crystalline environment of $\mathrm{Er}^{3+}$ ions. Thus, it seems that most of $\mathrm{Er}^{3+}$ ions in the PS matrix are located in the c-Si nanocrystallites.

The PL intensity $I$ at $18,235 \mathrm{~cm}^{-1}$ for erbiumdoped PS depends on temperature and is given by [8-10]:

$I \alpha \frac{N \tau}{\tau_{\text {tr }} \tau_{\text {rad }}[1+W \exp (-E / K T)]}$ 
where $\tau$ is the PL lifetime of erbium, $\tau_{\text {rad }}$, the radiative lifetime of the ion, $\tau_{\mathrm{tr}}$, the lifetime required for energy transfer and $\tau$ is the lifetime of erbium. $E$ is the energy gap between the conduction band and the erbium related level. $W$ is defined as $W=\sigma_{\mathrm{n}} n_{\mathrm{c}} / \sigma_{\mathrm{p}} G \tau_{\mathrm{c}}$, with $\tau_{\mathrm{c}}$ being the carrier lifetime and $n_{\mathrm{c}}$ being the density of state at the bottom of the conduction band, $G$, the optical generation rate of $\mathrm{e}-\mathrm{h}$ pairs, and $\sigma_{\mathrm{p}}, \sigma_{\mathrm{n}}$ are the capture cross-section for electron and holes, respectively.

Fit of this Eq. (1) to the data in Fig. 3 is shown as solid line. It is evident that Eq. (1) has the right functional form to describe the experimental results. In fact the intensity $I$ has a constant value at low temperatures while at higher temperatures it decreases with an activation energy $E$ of $0.206 \mathrm{eV}$. For erbium doping crystalline silicon, the value of $E$ measured by DLTS analysis is $0.15 \mathrm{eV}$ [8]. In other work [9], the authors have shown that for erbium-doped PS (using the implantation technique) the activation energy is $E=0.104 \mathrm{eV}$. The defect induced energy level at $E=0.206 \mathrm{eV}$ below the conduction band constitute a trap for the photogenerated carriers and bound excitons are formed. The energy of the recombined excitons is subsequently transferred to the $\mathrm{Er}^{3+} 4 \mathrm{f}$ shell. At low temperature, we assist to the formation of bound excitons and energy transfer to $\mathrm{Er}^{3+}$. However, with increasing the temperature, the formed bound exciton can be dissociated which reduces the excitation efficiency. The energy backtransfer from an excited $\mathrm{Er}^{3+}$ to a trapped carrier state decreases the excited state lifetime, and with it the luminescence efficiency. Quenching can also occur by Auger energy

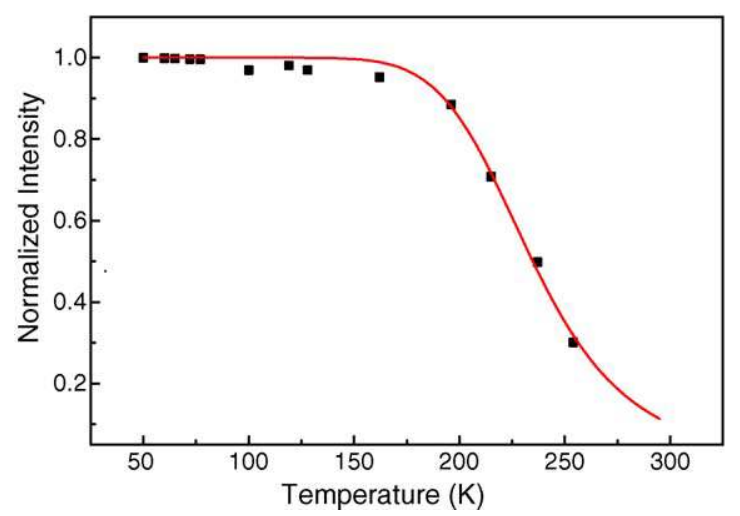

Fig. 3. PL intensity of erbium in PS as a function of temperature, the solid line is the best fit from Eq. (1). transfer to free carriers [11], if these are present in sufficiently high concentration. We note that both exciton dissociation and backtransfer processes are phonon-assisted. In this study (PS:Er) the PL quenching with temperature is relatively important because the energy $E$ is approximately only three times the energy of a TO phonon of PS, so, the probabilities of exciton dissociation and backtransfer increase with temperature. The excitation mechanism of $\mathrm{Er}^{3+}$ in PS is summarized in Fig. 4.

$E=0.206 \mathrm{eV}$ is comparable to that in c-Si substrate $(0.15 \mathrm{eV})$ so, the thermal quenching of PL intensity is important. This can be explained by a deeper incorporation of erbium from electrochemical method as shown from RBS and EDX measurements. For the immersed method, the thermal quenching of both PL intensity and PL lifetime were found to be weak [12] compared to the implanted technique. The authors [12] suggest that erbium-doped in PS from the immersed method is located at the surface of PS.

We have shown in previous work that energy transfer from PS to $\mathrm{Eu}^{3+}$ or $\mathrm{Tb}^{3+}$ is not the principal route for radiative transition $[4,13]$. This is because $\mathrm{Eu}^{3+}$ and $\mathrm{Tb}^{3+}$ ions are incorporated with the immersed method, so RE ions are localized essentially in the PS surface which is dominated by stoichiometric $\mathrm{SiO}_{2}$. Consequently no evidence of carrier-mediated excitation was reported for either $\mathrm{Eu}^{3+}$ or $\mathrm{Tb}^{3+}$ luminescence. The c-Si nanocrystallites in the surface have small size than those into the layer. As the band gap increases with size decrease of c-Si nanocrystallites,

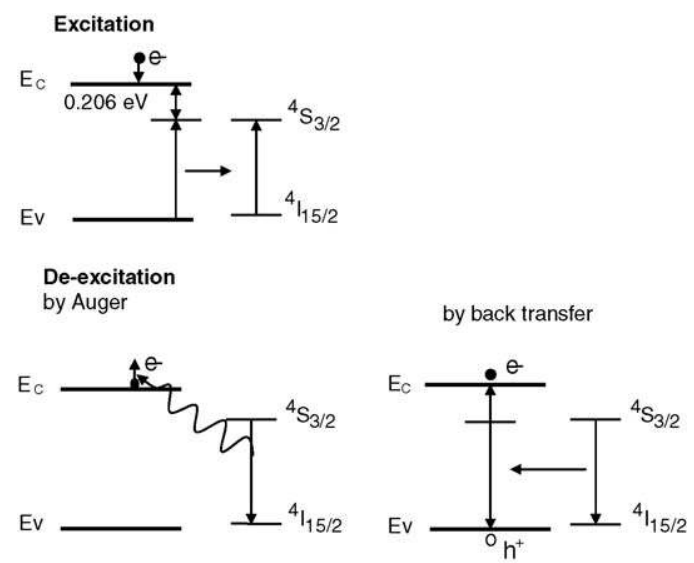

Fig. 4. Schematic of excitation and emission processes in erbiumdoped PS. 
we think that the $\mathrm{Er}^{3+}$-related level defect is localized deeply in the gap which can limit the processes of exciton dissociation and backtransfer because the phonon energy is weak compared to the value of $E$ in this case. As it has been shown for implanted method, in the present study, $\mathrm{Er}^{3+}$ ions are located essentially in the Si crystallites of the middle part of the layer. The band gap of these crystallites is not important relatively to the band gap of c-Si substrate. It is known that thermal quenching depends strongly on the band gap of the semiconductor because as the band gap is large as the energy $E$ of RE related defect increases, which reduces the back transfer and Auger quenching processes.

To gain further insight into the excitation mechanism of erbium ions in PS, study of the dependence of the PL intensity on the pump intensity, is performed (Fig. 5). The green PL intensity increased nearly linearly for low pump intensity and saturation was observed at pump intensities, relatively high, above $60 \mathrm{~W} / \mathrm{cm}^{2}$. The pump intensity dependent PL data were modelled within a simplified three-level erbium scheme [14]. It can be shown that the pump intensity dependence of the visible PL from erbium is given by [14]:

$I_{\mathrm{PL}}=\frac{I_{\mathrm{PLmax}}}{1+\frac{\tau^{-1} h c}{\sigma_{\mathrm{ex}} p_{\mathrm{ex}} \lambda_{\mathrm{ex}}}}$

where $I_{\mathrm{PLmax}}$ is the maximum PL intensity, $h$, the Plank's constant, $c$, the speed of light, $p_{\mathrm{ex}}$, the pump power, and $\lambda_{\text {ex }}$ is the excitation wavelength. Fitting the experimental data of Eq. (2), an estimate of the excitation cross-section $\sigma_{\mathrm{ex}}$ can be obtained. The fitting

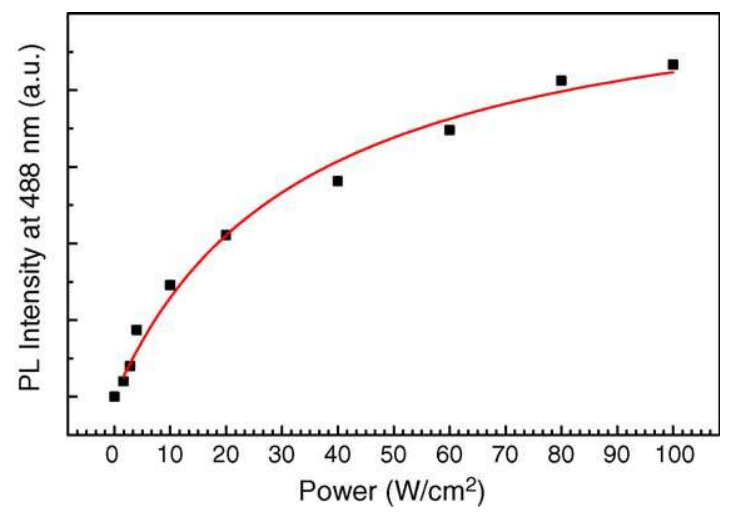

Fig. 5. Green PL intensity of erbium-doped PS as a function of a pump power. The solid line is the best fit from Eq. (2). yielded $\sigma_{\mathrm{ex}}=1.2 \times 10^{-19} \mathrm{~cm}^{2}$ with $\lambda_{\mathrm{ex}}=488 \mathrm{~nm}$ and $\tau=1 \mathrm{~ms}$ being fixed parameters. This value for the $\sigma_{\mathrm{ex}}$ seems reasonable compared to the cross-section of erbium transition in other host materials [14]. In particularly, $\sigma_{\mathrm{ex}}$ is nearly that of erbium ions in $\mathrm{nc}-\mathrm{Si}$ implanted in $\mathrm{SiO}_{2}$. As it has been suggested by Kenyon et al. [15], the saturation of the PL intensity with pump power is due to the fact that the luminescence is limited by the availability of $\mathrm{Er}^{3+}$ in close proximity to silicon nanocrystals. Consequently, the optical cross-section increases compared to that in stoichiometric $\mathrm{SiO}_{2}$ where the $\mathrm{Er}^{3+} \mathrm{PL}$ intensity does not saturate (for the same $\mathrm{Er}^{3+}$ concentration in silicon nanocrystals) because the PL yield is not constrained by the availability of $\mathrm{Er}^{+3}$ ions but rather by the small absorption cross-section. Thus, it seems that most of $\mathrm{Er}^{3+}$ ions incorporated in PS from the electrochemical method is localized in c-Si nanocrytallites.

\section{Conclusion}

PS is doped with erbium ions by using the electrochemical deposition. A relatively uniform incorporation of erbium ions in the PS layer was evidenced from RBS and EDX analysis. In the presence of erbium, new well-defined luminescent centres are formed. The formation of these sites results in the creation of a defectrelated level in the band gap at $0.206 \mathrm{eV}$ below the conduction band. The weak temperature quenching of the erbium PL intensity is explained by both back transfer and Auger processes. Pump intensity dependent PL studies revealed that the excitation cross-section is the order of $1.2 \times 10^{-19} \mathrm{~cm}^{2}$. The present results suggest that PS doped with erbium appears to be very attractive material for optical waveguide at $1.53 \mu \mathrm{m}$.

\section{Acknowledgements}

The authors would thank Mr. R. Chtourou from the INRST for the PL measurements in the IR game.

\section{References}

[1] K.D. Hirschman, L. Tsybeskov, S.P. Duttagupta, P.M. Fauchet, Nature (London) 384 (1996) 338. 
[2] F. Namovar, F. Lu, C.H. Perry, A. Cremins, N.M. Kalhorau, J.T. Daly, R.A. Soref, Mater. Res. Soc. Symp. Proc. 358 (1995) 375.

[3] A.M. Dorofeev, N.V. Gaponenko, V.P. Bondarenko, E.E. Bachilo, N.M. Kazuchits, A.A. Leshok, G.N. Troyanova, N.N. Vorosov, V.E. Borisenko, J. App. Phys. 77 (1995) 2679.

[4] A. Moadhen, H. Elhouichet, M. Oueslati, M. Férid, J. Lumin. 99 (2002) 13.

[5] H.A. Lopez, X.L. Chen, S.A. Jenekhe, P.M. Fauchet, J. Lumin. 80 (1999) 115.

[6] T. Kumura, A. Yokoi, H. Horigrechi, R. Saito, T. Ikoma, A. Sato, Appl. Phys. Lett. 65 (1994) 983-985.

[7] W. Jantsch, S. Lanzerstorfer, L. Palmetshofer, M. Stepikhova, G. Kocher, H. Preier, Physica B 273/274 (1999) 944-946.

[8] F. Priolo, G. Franzò, S. Coffa, A. Polman, S. Libertino, R. Barklie, D. Carey, J. Appl. Phys. 78 (6) (1995) 3874-3882.
[9] X. Wu, R. White, U. Hömmerch, F. Namavar, A.M. CreminsCosta, J. Lumin. 71 (1997) 13.

[10] H. Elhouichet, M. Oueslati, N. Lorrain, S. Langa, I.M. Tiginyanu, H. Föll, Phys. Stat. Sol. (a) 202 (8) (2005) 1513 1517.

[11] S. Coffa, G. Franzò, F. Priolo, Appl. Phys. Lett. 69 (1996) 2077.

[12] W. Wang, H. Isshiki, S. Yugo, R. Saito, T. Kimura, J. Lumin. 87 (9) (2000) 319.

[13] H. Elhouichet, A. Moadhen, M. Oueslati, M. Férid, J. Lumin. 97 (2002) 34-39.

[14] J.T. Seo, U. Hömmerch, D.C. Lee, J. Heikenfeld, A.J. Steckel, J.M. Zavada, J. Alloys Compd. 341 (2002) 62-66.

[15] A.J. Kenyon, C.E. Chryssou, C.W. Pitt, T. Shimizu-Iwayama, D.E. Hole, N. Sharma, C.J. Humphreys, J. Appl. Phys. 91 (2002) 367. 